\title{
MATERIAL CONCRETO: UMA ESTRATÉGIA PEDAGÓGICA NO ENSINO E APRENDIZAGEM DE MATEMÁTICA
}

\author{
Kellen Christine Jager SILVA* \\ Valéria Gomes da SILVA**
}

Resumo: O presente artigo visa descrever a importância do uso do material concreto e lúdico no ensino da matemática. Sabemos que muitos professores em suas práticas de ensino usam somente o livro didático e caderno de planejamento para ministrarem suas aulas. Com toda informação que existe hoje, nossos alunos necessitam mais que isso, para que as aulas fiquem motivadas. Utilizando o material concreto as aulas podem ficar mais atrativas motivando os alunos a participarem de maneira prazerosa. Este artigo tem como foco a concepção e a ação docente na organização das situações de ensino e aprendizagem com o manuseio de materiais concreto na disciplina de matemática nos anos iniciais do ensino fundamental. $\mathrm{O}$ estudo apoia-se numa pesquisa bibliográfica. Os resultados desse estudo demonstram que quando o professor promove um espaço lúdico revelado nos jogos e nos materiais concretos, os alunos interagem cooperativamente neste espaço organizado pelo docente, comprovando, portanto, a importância da intervenção pedagógica para a construção de relações cognitivas que se traduzem em aprendizagem.

Palavras-chave: Matemática, Material Concreto, Ensino e aprendizagem, Ensino Fundamental.

\footnotetext{
* Especialista em Coordenação Pedagógica pela Universidade Federal de Uberlândia(UFU). kellenjager@hotmail.com

*** Mestre em Educação pela Universidade Federal de Uberlândia. gomesvaleria@hotmail.com
}

(C) Silva; Silva - DiversaPrática, v. 4, n. 1, p. 16-42 - $1^{\circ}$ semestre 2017 
Abstract: The present article aims to describe the importance of the use of concrete and playful material in the teaching of mathematics. We know that many teachers in their teaching practice use only the textbook and planning notebook to teach their classes. With all the information that exists today, our students need more than this, so that the classes are motivated. By using the concrete material the lessons can be more attractive by motivating students to participate in a pleasurable way. This article focuses on the conception and the teaching action in the organization of teaching and learning situations with the handling of concrete materials in the discipline of mathematics in the initial years of elementary education. The study is based on a bibliographical research. The results of this study demonstrate that when the teacher promotes a playful space revealed in games and concrete materials, students interact cooperatively in this space organized by the teacher, proving, therefore, the importance of pedagogical intervention for the construction of cognitive relations that translate into learning.

Keywords: Mathematics, Concrete Material, Teaching and learning, Elementary School.

\section{INTRODUÇÃO}

O presente artigo trata dos resultados de uma pesquisa bibliográfica sobre o material concreto: uma estratégia pedagógica no ensino de Matemática. Essa pesquisa foi norteada pela busca de resposta da seguinte indagação: Quais são as contribuições do material manipulativo ou concreto nos processos de ensino e aprendizagem da 
matemática nos primeiros anos do Ensino Fundamental?

Diante desta questão, pretendeu-se com o estudo realizado, discutir quais são as contribuições de materiais manipulativos nos processos de ensino e aprendizagem da disciplina de Matemática nos primeiros anos do Ensino Fundamental. Além disso, também buscouse de forma específica, refletir a utilização de materiais manipulativos como recursos didáticos nos processos de ensino e aprendizagem da matemática; bem como apresentar uma proposta de ensino com base na manipulação de materiais concreto no ensino de matemática.

Este estudo se justifica, pelo fato de que o professor nem sempre tem clareza das razões fundamentais pelas quais os materiais ou jogos são importantes nos processos de ensino e aprendizagem da matemática. Geralmente, eles não questionam se os materiais concretos são necessários nas práticas de ensino e aprendizagem, e em que momentos devem ser utilizados. Como professora atuante na rede pública de ensino, conheço todas as dificuldades de conseguir um material concreto.

Sabemos que, no decorrer da educação formal, os jogos são deixados de lado por grande parte dos professores que acreditam ser este um desperdício de tempo e pela dificuldade em encontrar esses materiais na escola. Porém, acredito na importância do lúdico na aprendizagem e, por isso, busco respostas em nossa prática de ensino 
para algumas questões referentes à aprendizagem.

Para responder adequadamente ao problema da pesquisa e alcançar os objetivos pretendidos foi desenvolvido um estudo de natureza bibliográfico. Entendida a pesquisa bibliográfica como um tipo de investigação científica que busca, a partir do estudo planejado de obras escritas que tratam da mesma temática, dentre as quais, artigos, livros, dissertações e teses, preferencialmente aquelas que foram publicadas recentemente, dar respostas a indagações que são consideradas importantes para determinada área do conhecimento.

A pesquisa bibliográfica colabora efetivamente para a ampliação de saberes, sejam eles de natureza teórica ou prática, uma vez que possibilita a sistematização de conhecimentos que outros pesquisadores, por meio de suas investigações, conseguiram analisar, organizar e disponibilizar para que outros interessados tenham acesso e deles façam uso.

A pesquisa bibliográfica realizada se baseou, dentre outros, nos estudos de Melo e Sardinha (2009), Santos e Oliveira e Silva (2004). 


\section{DESENVOLVIMENTO}

\section{Conceitos matemáticos numa perspectiva histórica}

Para realizar contagens e resolver problemas criou-se a matemática. É uma ciência que tem finalidades práticas e é considerada como parte da construção da cidadania. Desde sempre a matemática foi e sempre será uma ampla necessidade humana. No princípio houve a necessidade de desenvolver conhecimentos matemáticos para comercialização de produtos e objetos.

Nesse contexto, observa-se que historicamente os princípios básicos da matemática desenvolveram-se e desta forma foram sendo aperfeiçoados. É possível constatar que grandes matemáticos, que ainda exercem fundamental significado atualmente, sugiram antes de Cristo, e possuem relevância para a humanidade, pois descobriram novas fórmulas, soluções e cálculos. Desta forma, pode-se perceber que a inteligência do homem está associada ao desenvolvimento matemático, pois há estrita relação no processo histórico de ambas.

Nota-se que vários povos se destacaram no que se refere ao desenvolvimento matemático. Os primeiros povos a usar a matemática foram os babilônios e os egípcios. A utilização matemática, por esses povos, objetivava apenas atender as necessidades básicas individuais e coletivas, isso porque a matemática para estes povos não era usada 
como conhecimento. Vale destacar que os babilônicos aplicaram a matemática para aprender e construir modelos, através de objetos concretos. Os métodos empregados pelos babilônios permaneceram por muito tempo, pois por meio destes eles aprenderam e obtiveram descobertas de maneira concreta e não apenas de forma abstrata.

Com os avanços e as transformações ocorridas durante vários séculos, essa visão tradicionalista do ensino da matemática evidencia constantes transformações. Entre outras pesquisas sobre o assunto apontam que o ensino da matemática deve acontecer por meio do material concreto, pois desta forma a criança tem possibilidades de se identificar com a disciplina. Para tanto, pressupõe-se que o material concreto e a mediação do educador, estarão juntos, proporcionando uma compreensão melhor para os alunos, favorecendo a resolução dos problemas no dia a dia da sua realidade.

Os Parâmetros Curriculares Nacionais (PCN, 1998) reforçam o argumento quando se percebe a História da Matemática como um valioso recurso didático, uma vez que, ao se fazer a abordagem de conceitos matemáticos em sua amplitude histórica, será possível a veiculação de informações culturais, sociológicas e antropológicas que são de grande valor formativo e enriquecem a aprendizagem do aluno. Além disso, "ao verificar o alto nível de abstração matemática de algumas culturas antigas, o aluno poderá compreender que o avanço 
tecnológico de hoje não seria possível sem a herança cultural de gerações passadas" (PCN, 1998, p. 42). Tais afirmações possibilitam ao professor responder a alguns porquês dos alunos durante as aulas, contribuindo para a construção de uma perspectiva mais crítica e reflexiva acerca dos conteúdos estudados, concedendo-lhes seu devido grau de importância e contribuição para diversos setores da sociedade. Para além do uso da história da matemática, há diversas pesquisas voltadas para a relevância de outros componentes como os jogos e softwares computacionais que também se apresentam como importantes recursos para promover os processos de abstração de conceitos matemáticos como também a manipulação destes.

\section{A importância do material concreto no ensino da Matemática}

O ensino e a aprendizagem da matemática desenvolvido atualmente por meio de aulas expositivas provoca no aluno um comportamento passivo, acatando e executando apenas as ideias do professor. Diante desses fatos, a falta de interesse e o péssimo desempenho do aluno na disciplina de matemática, muitas vezes, estão vinculados às metodologias e às estratégias de ensino abordadas pelo professor em sala de aula.

Assim, de modo geral, ensino desenvolvido mediante a 
pedagogia tradicional não condiz com a realidade do aluno. Os alunos de hoje estão imersos em um mundo muito diferente daquele de décadas atrás. Eles trazem uma experiência mais atravessada pela tecnologia, pela mídia. Nesse sentido, possuem conhecimentos e experiências que não estão mais restritos ao âmbito da família e da escola, mas se processam nas interações com a mídia e com os mais diversos meios de informação. Desse modo, não podemos dar aulas hoje como tivemos aula quando éramos alunos.

O ensino e a aprendizagem de matemática caracteriza-se ainda hoje como uma transmissão de conhecimento, onde o professor é o centro das atenções e o aluno um mero expectador. A metodologia de ensino muitas vezes não está em consonância com o aspecto social do estudante, onde ele poderia se envolver mais com as aulas.

Nesse sentido, a adoção de jogos para o ensino vem se tornando um amparo preciso para a facilitação da aprendizagem, onde a sua utilização pode tornar mais significativa e prazerosa as aulas de matemática, superando o caráter formalista que a envolve.

Aprender matemática na visão dos alunos não é uma tarefa fácil. É comum encontrar alguns alunos dizendo que não são bons em matemática. Segundo Smole (2007) a utilização de jogos nas escolas não é algo novo e implica uma mudança significativa na dinâmica das aulas, que anteriormente só usavam como recurso o livro didático. O 
trabalho através da manipulação de objetos possibilita o desenvolvimento da criança em habilidades como discriminação e memória visual:

É muito difícil, ou provavelmente impossível, para qualquer ser humano caracterizar espelho, telefone, bicicleta ou escada rolante sem ter visto, tocado ou utilizado esses objetos. Para as pessoas que já conceituaram esses objetos, quando ouvem o nome do objeto, sem precisarem dos apoios iniciais que tiveram dos atributos tamanho, cor, movimento, forma e peso. Os conceitos evoluem com o processo de abstração; a abstração ocorre pela separação. (LORENZATO, 2006, p.22).

Nesse sentido, o professor, consciente que os resultados satisfatórios não estão sendo alcançados, deve repensar o seu fazer pedagógico, procurando novos elementos que acredita poder melhorar esse quadro. Para Kamii (1990), “dizer que a criança deve construir seu próprio conhecimento não implica que o professor fique sentado, omitase e deixe a criança inteiramente só." (KAMII 1990, p.48). Isso significa que ele deve ser o mediador, o incentivador, o organizador do processo de aprendizagem do aluno.

Não é recente a preocupação de professores para que as aulas de Matemática tornem-se encontros que propiciem uma aprendizagem significativa ao aluno. Por outro lado, sempre se buscou metodologias para facilitar seu ensino e, consequentemente, sua aprendizagem. Ao 
longo da história da educação, destacam-se professores, pesquisadores e pensadores que se dedicaram ao estudo de instrumentos para auxiliar no estudo dessa ciência. Prova disso são os diversos jogos e materiais manipuláveis existentes. A preocupação com o ensino significativo está presente também nos documentos oficiais.

Com a promulgação da Lei de Diretrizes e Bases da Educação Nacional, Lei $n^{\circ}$ 9.394/1996, foram elaborados diversos documentos para que professores, pedagogos e gestores pudessem ter um norte de que forma trabalhar a Matemática para que esta ciência promovesse, dentre outras habilidades, autonomia e reflexão aos educandos, preparando-os para uma sociedade complexa. Dentre esses documentos, destacam-se os PCN $^{2}$; PCNEM PCN $^{3} \mathbf{P C N}^{4}$; e OCEM.

É importante o professor compreender que o aluno deve ter um papel ativo na construção do seu conhecimento, e que a Matemática não é como uma ciência que se utiliza somente de aplicação de fórmulas e resolução de algoritmos. A distorção dessa compreensão pode ser entendida, percorrendo a trajetória da Matemática que foi introduzida em todas as séries do Ensino Secundário do Brasil em 1929, por Euclides Roxo. Durante muito tempo, o ensino dessa disciplina foi caracterizado pela repetição, memorização de fórmulas e reprodução de algoritmos, em que a metodologia se baseava na transmissão do conteúdo pelos professores. 
Nessa perspectiva, o estudante é entendido como sujeito passivo no processo de aprendizagem cabendo a ele reproduzir em situações semelhantes ao que foi abordado nas aulas. Frequentemente, os alunos e professores não contextualizam as fórmulas e os algoritmos apresentados, nem mesmo os livros didáticos nos trazem tal opção, o que os leva a terem um desempenho insatisfatório quando submetidos à resolução de problemas ou diante de alguma avaliação. $\mathrm{O}$ ensino transmissivo dominou a sala de aula durante séculos, porém essa concepção tem sido transformada pela evolução das teorias cognitivas e o surgimento de novas metodologias de ensino que potencializam a contextualização do saber, a compreensão de regras e a articulação de representações matemáticas.

O movimento da Educação Matemática é conduzido por pesquisadores e especialistas da área da Educação e da Matemática, que acreditam na importância de considerar a realidade do aluno, possibilitando-o compreender e construir seu conhecimento matemático. Mesmo assim, a matemática tem sido abordada de forma abstrata, com poucas demonstrações concretas e problematização dos conceitos com a realidade, fato esse que dificulta o entendimento dos discentes e como consequência muitos passam a não gostar da área exata. E é nesse contexto, que os materiais concretos se configuram em uma possibilidade de recurso para ser inserido no currículo, criando o 
elo entre teoria e prática minimizando as rupturas da articulação do cotidiano para o saber escolar.

É sabido que o material concreto tem possibilitando aos estudantes estabelecerem relações entre as situações experenciadas na manipulação de tais materiais e a abstração dos conceitos estudados. Assim é fundamental, que o professor desenvolva uma proposta pedagógica que integre o material concreto definindo antecipadamente os objetivos a serem cumpridos e metas a alcançar, estabelecendo vínculos com o contexto social dos alunos. Não é somente levar jogos para a sala de aula, precisa ter em mente os objetivos a serem trabalhados. Trata-se de criar condições de aprendizagem que permitam a inserção dos conceitos em situações nas quais os alunos tenham maiores condições de compreender o sentido do saber.

O professor ao abordar um novo conteúdo ele deve incluir em sua prática de ensino atividades práticas, recorrendo ao uso de materiais concretos, que segundo Piaget (1896-1980) fica evidente o melhor desenvolvimento da aprendizagem do aluno.

Segundo o autor a aprendizagem da matemática envolve o conhecimento físico e o lógico-matemático. O primeiro ocorre quando o aluno observa, analisa, identifica e opera o material. Já o segundo, se dá quando ele usa apenas os atributos dos materiais ou opera sem tê-los em mãos, momento que também desenvolve o próprio raciocínio 
abstrato.

O material concreto no trabalho em sala de aula, além de ser um meio de diversão, favorece o desenvolvimento do raciocínio lógico, da coordenação motora, a socialização e concentração, fatores fundamentais para a compreensão e resolução problemas matemáticos.

Porém, é imprescindível que o trabalho com o material concreto seja realizado de forma direcionada para que o aluno possa construir o conhecimento matemático. Nesse sentido, o professor deve ser o mediador e o incentivador nos processos de ensino e aprendizagem.

O uso do material concreto em sala de aula é uma forma de apresentar ao aluno uma maneira mais fácil e palpável de aprender a matemática além de enriquecer a aula, esse recurso pedagógico estimula o interesse e a criatividade do aluno, tornando a aula participativa e proveitosa.

A utilização de jogos para o ensino vem se tornando um amparo preciso para facilitar a aprendizagem, tornando as aulas de matemática mais significativas e prazerosas, superando o caráter formalista de como ela é desenvolvida no cotidiano da sala de aula.

Utilizar o material concreto por si só não garante aprendizagem. É fundamental o papel do professor nesse processo, enquanto mediador da ação e articulador das situações experenciadas no material concreto e os conceitos matemáticos, para uma posterior abstração e 
sistematização.

Com a publicação da (LDB) Lei de Diretrizes e Bases da Educação Nacional, Lei $n^{\circ}$ 9.394/1996, foram criados diversos documentos para que docentes e gestores pudessem ter orientação de como trabalhar a matemática para que essa promovesse, dentre outras habilidades, autonomia e reflexão aos estudantes.

Além da LDB, os (PCNs) Parâmetros Curriculares Nacionais (1997) também destacam a utilização de materiais concretos pelos professores como um recurso alternativo que pode tornar muito significativo os processos de ensino e aprendizagem da matemática.

A esse respeito os PCNs (1997),

Visam à construção de um referencial que oriente a prática escolar de forma a contribuir para que toda criança e jovem brasileiros tenham acesso a um conhecimento matemático que lhes possibilite de fato sua inserção, como cidadãos, no mundo do trabalho, das relações sociais e da cultura. Quanto aos conteúdos, apresentam um aspecto inovador ao explorá-los não apenas na dimensão de conceitos, mas também na dimensão de procedimentos e de atitudes. (BRASIL, 1997)

Por isto, se o professor prepara uma aula onde os alunos têm acesso à materiais para manipular, terá maiores chances de sucesso, tendo em vista as reais possibilidades dos alunos desenvolverem ações que lhes propiciem a construção de um saber consistente e significativo. 
De acordo com os PCNs de matemática, um dos princípios norteadores do ensino de matemática no Ensino Fundamental é a utilização dos recursos didáticos numa perspectiva problematizadora.

Sobre essa questão os PCNs (1997) ressaltam que:

Recursos didáticos como livros, vídeos, televisão, rádio, calculadora, computadores, jogos e outros materiais têm um papel importante no processo de ensino e aprendizagem. Contudo, eles precisam estar integrados a situações que levem ao exercício da análise e da reflexão. (BRASIL, 1998, p. 57)

É sabido que muitas vezes a escola não tem alguns recursos didáticos que atendam aos conteúdos desenvolvidos em sala de aula. Além disso, muitos professores não utilizam o material por falta de conhecimento, ou o uso se restringe a ludicidade, sem articulação conceitual com a Matemática.

Ressalto que o docente pode confeccionar o seu material concreto, sem se apegar a alguns materiais que a escola possui. Há vários materiais concretos que podem ser feitos pelo próprio professor juntamente com os alunos, e que possuem baixo custo. A seguir, na imagem é mostrado um exemplo de duas mãos recortadas em papel colorido utilizadas para trabalhar conceitos de adição e subtração. 
Fotografia 1 - Ilustração de um material concreto: utilizado nas aulas de matemática.

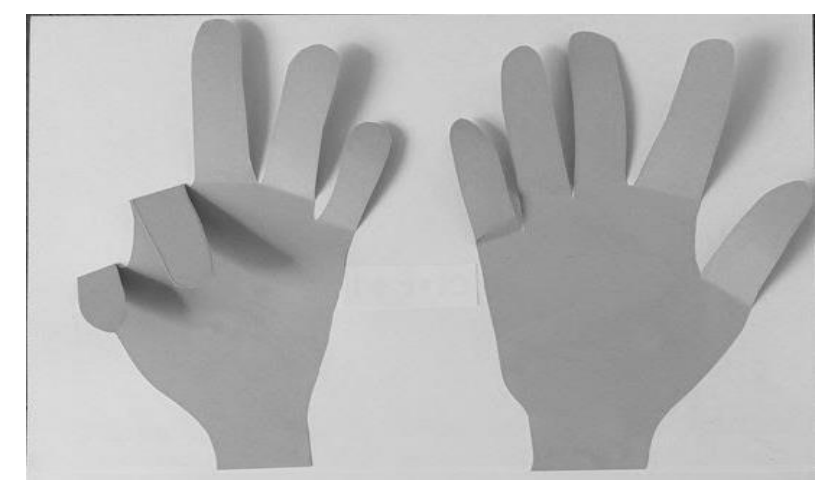

Fonte:http://beteramos.blogspot.com.br/2014/05/adicao-esubtracao.html

E com elas você pode trabalhar:

- Contagem: o professor escolherá alguns números de 0 a 10 e pedirá ao aluno que represente nas mãozinhas os algarismos selecionados. Para isso, o aluno dobrará para baixo os dedinhos que não vai usar para representar a quantidade.

- Operações de adição simples: a criança usará as duas mãozinhas para somar quantidades até 10 que podem ser ditas pelo professor oralmente, ou para resolver operações escritas em folha.

- Operações de subtração simples: usando as mãozinhas para diminuir as quantidades. Aproveitando para deixar bem claro que na subtração, 
diminuímos ou tiramos de uma quantidade que temos.

Por exemplo, $5-2=3$

De 5 dedos que eu tenho, eu vou tirar dois dedos e vai sobrar...

Essa compreensão é bem abstrata e deve ser bem trabalhada pelo professor.

Usando materiais diferentes em sala, as crianças se sentem mais interessadas nas aulas e acham que estão "brincando". As aulas são mais prazerosas e rendem mais.

Inovar o ensino da matemática geralmente relaciona-se com o desenvolvimento de novas metodologias de ensino que complementem o conteúdo trabalhado com o objetivo de desenvolver a autonomia dos alunos bem como seu conhecimento lógico matemático analisado dentro de uma visão interativa e autônoma, na formação de indivíduos autônomos, capazes de raciocinar de forma independente, participativo e criativo (KAMMI, 1995, p. 45).

O material concreto é uma forma de apresentar ao aluno uma maneira mais fácil e palpável de aprender matemática e como ela pode ser usada no nosso cotidiano. Se existe uma diversidade de materiais elaborados com a finalidade de melhorar a aprendizagem do indivíduo é cabível o uso desses materiais para enriquecer as aulas de matemática, estimular a criatividade dos alunos e tornarem-se menos exaustivas. 
Na utilização de materiais concretos em sala de aula, o aluno centra-se em observar, relacionar, comparar hipóteses e argumentações; o professor é incumbido de orientar na resolução das tarefas. É importante também para o aspecto tomar interesse em atuar em grupo e o desenvolvimento cognitivo, preferencialmente nas séries iniciais.

\subsubsection{A utilização dos materiais concretos}

Quando se faz uso de materiais concretos para a transmissão do conhecimento matemático propicia a evolução do pensamento dos alunos. Eles vão deixar de esperar a resposta pronta e acabada e desenvolverão suas ideias, traçando estratégias para resolver os problemas, sem medo de arriscar.

Conforme os PCNs (2000), um dos aspectos importantes dos jogos é que eles provocam nos alunos um desafio verdadeiro, fazendo com que tenham ao mesmo tempo mais interesse e prazer pela disciplina. Além disso, os jogos possibilitam que os bloqueios apresentados pelos alunos sejam diminuídos. Os alunos interagem mais.

$\mathrm{O}$ aluno precisa ter um conhecimento mínimo sobre o material a ser utilizado. Ele necessita ter uma imagem do objeto a ser usado. Por exemplo, na utilização do material dourado se o estudante não compreende o sistema decimal vê a barra que representa a dezena como algo não muito diferente do cubinho que significa unidade. A 
organização estrutural deve ser percebida pelo aluno, cabendo ao professor explorar, juntamente com os alunos, todos os aspectos que o material oferece para alcançar o planejamento de ensino.

A escolha do material a ser utilizado deve obedecer, além do aspecto desafiador e de interesse, ao grau de desenvolvimento dos alunos, a idade e o nível de entendimento que ele traz ao ingressar na escola. Quando o objetivo de jogos é a aprendizagem, esta deve estar sempre orientada para atingir objetivos pertinentes ao desenvolvimento escolar e social dos educandos.

\subsection{Recursos didáticos no ensino da matemática}

"Aqueles que não acreditam na importância do material didático no ensino da Matemática ou que até condenam mesmo o seu uso, foram, provavelmente, influenciados pela observação de um mau emprego desse material" (JANUARIO, 2008, p. 34)

Entende-se por recurso didático todo componente que venha a auxiliar o trabalho do professor em sala de aula e venha a trazer subsídios para a aprendizagem dos alunos de forma mais prazerosa. Sua utilização tal como o tratamento dado ao tema é algo bastante discutido na educação brasileira. No campo do ensino da matemática, sua utilização faz-se ainda mais cautelosa e necessária. 
Para o professor dos primeiros anos do Ensino Fundamental, que ensina matemática, existem diversos recursos didáticos dentre eles os materiais concretos nos quais o docente pode se apoiar na sua prática pedagógica. A seguir serão apresentados alguns materiais concretos que podem ser utilizados no espaço da sala de aula durante a abordagem de conteúdos matemáticos.

O trabalho do professor é indispensável ao fazer uma criteriosa seleção dos materiais que devem englobar os recursos didáticos objetivando resultados satisfatórios em termos de aprendizagem. Essa seleção deve optar por materiais que proporcionem uma verdadeira personificação das ideias a serem exploradas e do conceito matemático, representando-o claramente, sendo motivadores.

A utilização de materiais concretos na aprendizagem de matemática está aliada ao fato de eles oferecerem um conceito de diversão, de brincadeira para os alunos. Isso faz com que ocorra um maior interesse e envolvimento por parte deles, pois proporciona algo diferente do que ocorre em sala de aula no cotidiano, acabando por deixá-los mais animados e dispostos para as aulas.

Eles provocam uma reflexão e o estabelecimento de relações lógicas pelos alunos. Ou seja, acaba por provocar além do desafio e da diversão, o pensamento reflexivo dos alunos. Eles contribuem também para estimular o senso de iniciativa. Infere-se que a adoção do lúdico 
nas aulas de matemática pode proporcionar uma melhor interação entre professor e aluno, pois o último torna-se mais participativo e com isso contribui para que as aulas tornem-se mais produtivas.

Como são vários, os materiais como o tangram, material dourado, blocos lógicos, ábaco dentre outros, é possível desenvolver atividades utilizando esses materiais que podem ser confeccionados de papel, cartolina, papelão dentre outros. E por isso podem ser construídos na própria sala de aula e com a participação dos alunos.

Ábaco: é um antigo instrumento de cálculo, formado por uma moldura com bastões ou arames paralelos, dispostos no sentido vertical, correspondentes cada um a uma posição digital (unidades, dezenas) e nos quais estão os elementos de contagem (fichas, bolas, contas) que podem fazer-se deslizar livremente. Teve origem provavelmente na China e no Japão, há mais de 5.500 anos. O ábaco pode ser considerado como uma extensão do ato natural de se contar nos dedos. Emprega um processo de cálculo com sistema decimal, atribuindo a cada haste um múltiplo de dez. Ele é utilizado ainda hoje para ensinar às crianças as operações de somar e subtrair.

Blocos Lógicos: são conjunto de pequenas peças geométricas divididas em quadrados, retângulos, triângulos e círculos e tem por finalidade auxiliar na aprendizagem de crianças na educação infantil e educação básica. Podem ser confeccionados em madeira, plástico ou 
cartolina com diferentes tamanhos, espessura e cores. Podem ser adquiridas em estabelecimentos especializados em materiais pedagógicos.

Material Dourado: é um dos materiais idealizados pela médica e educadora Montessori. Ele tem como foco o trabalho com a matemática. Apesar de ter sido elaborado para o trabalho com aritmética, seguiu os mesmos princípios montessorianos sobre a educação sensorial.

Tangram: é um quebra-cabeça chinês formado por 7 peças. Com essas peças podemos formar várias figuras, utilizando todas elas sem sobrepô-las. Segundo a Enciclopédia do Tangram é possível montar mais de 5000 figuras. Esse quebra-cabeça, também conhecido como jogo das 1000 peças, é utilizado pelos professores de geometria como instrumento facilitador da compreensão das formas geométricas. Além de facilitar o estudo da geometria, o Tangram estimula o desenvolvimento da criatividade e do raciocínio lógico.

Não se sabe ao certo como surgiu o tangram apesar de haver várias lendas sobre a sua origem e o seu nascimento no mundo dos mortos. Uma diz que uma pedra preciosa se desfez em sete pedaços, e com elas era possível formar várias formas. Outra diz que um imperador deixou um espelho quadrado cair, e este se desfez em 7 pedaços que poderiam ser usados para formar várias figuras, de diversas formas. 
Segundo algumas, o nome Tangram vem da palavra inglesa "tangam", de significado "misturas" ou "desconhecidos". Outros dizem que a palavra vem da dinastia chinesa Tang, ou até do barco cantonês "bundumocu", onde mulheres entretinham os marinheiros americanos. Na Ásia o jogo é chamado de "300 placas". O tangram é muito usado em trabalhos escolares para exposições e outros.

Disco de Frações: auxilia na visualização da representação gráfica de uma fração. Este auxilia não apenas na compreensão das noções de frações, como é um recurso excelente para a aprendizagem de equivalência. Cada peça tem, descriminada, sua fração correspondente.

\section{CONSIDERAÇÕES FINAIS}

Pelo exposto ao longo do texto ficou evidenciado que esse estudo objetivou contribuir como fonte de informação e reflexão para aquelas pessoas que estão no processo de formação acadêmica e para os profissionais da educação, que tem interesse de conhecer melhor o uso do material concreto no ensino da matemática especificamente nos primeiros anos do Ensino Fundamental, bem como a importância do mesmo para o desenvolvimento integral da criança. Acreditamos que esse trabalho e os demais já existentes podem beneficiar a sociedade na 
construção de uma educação de qualidade.

Diante do que foi proposto nesse artigo, é possível observar que o uso do material concreto, desde que trabalhado de forma dirigida, possibilita o conhecimento de forma diferente e ao mesmo tempo prazerosa. Um aspecto preocupante é que existem professores que usam esses materiais apenas como brinquedos e "passa tempo" sem terem a preocupação em fazer uma atividade dirigida que contribua significativamente para a formação dos alunos. Finalmente é possível dizer que os nossos objetivos propostos foram alcançados, nos deixando com a convicção de que o uso do material concreto pode contribuir para melhorar os processos de ensino e aprendizagem da matemática e desmistificar que a matemática é abstrata e difícil de aprender.

Ao docente, cabe rever sua prática de ensino e observar se suas aulas são inovadoras e contextualizadas e que possibilitam ao aluno desenvolver habilidades matemáticas de forma crítica e reflexiva. O não atendimento a essa demanda implica numa urgente incorporação dos recursos didáticos nas aulas de matemática, salientando seu uso consciente e adequado a cada situação. Em tais condições, o professor tem seu trabalho facilitado, as aulas se tornam prazerosas e o aluno é poupado de um ensino de matemática descontextualizado. 


\section{REFERÊNCIAS}

BRASIL. Lei de Diretrizes e Bases da Educação: Lei no 9.394/96 -

24 de dez. 1996. Estabelece as diretrizes e bases da educação nacional. Brasília, 1998.

BRASIL. Ministério da Educação e do Desporto. Secretaria de Educação Fundamental. Referencial Curricular Nacional para a Educação Infantil. Brasília, vol.1, 1998.

KAMII, C. A criança e número: Implicações educacionais da teoria de Piaget para a atuação com escolares de 4 e 6. Tradução A. de Assis. 11 ${ }^{a}$ ed. Campinas: Papirus, 1990.

LORENZATO, S. O Laboratório de Ensino de Matemática na Formação de Professores. Campinas: Autores Associados, 2006.

MELO, S. A.; SARDINHA, M. O. B. -5 jogos no ensino aprendizagem de matemática: uma estratégia para aulas mais dinâmicas. Revista F@pciência, Apucarana-PR, ISSN 1984-2333, v.4, n. 2, p. $5-15,2009$.

PIAGET, J. A Linguagem e o Pensamento da Criança. São Paulo: Martins Fontes, $6^{\mathrm{a}}$ ed. 1993.

SILVA, M. S. D.; Clube da Matemática: Jogos educativos -

(C) Silva; Silva - DiversaPrática, v. 4, n. 1, p. 16-42 - $1^{\circ}$ semestre 2017 
Campinas, SP: Papirus, 2004

SMOLE. K. C. S. A matemática na educação infantil: a teoria das inteligências múltiplas na prática escolar. Porto Alegre: Artmed, 2000.

TOLEDO, M. TOLEDO, M. Didática da matemática: com a construção da matemática. São Paulo: FTD, 1997. 